\title{
Eosinophil-active chemokines: assessment of in vivo activity
}

M.M. Teixeira

Correspondence

M.M. Teixeira

Departamento de Farmacologia

ICB, UFMG

Avenida Antonio Carlos, 6627

3127-901 Belo Horizonte, MG

Brasil

Fax: 55 (031) 441-0835

E-mail:mmtex@mono.icb.ufmg.br

Presented at the International Meeting on Cytokines, Angra dos Reis, RJ, Brasil, November 24-28, 1996.

At the time of presenting this study, M.M. Teixeira was a postdoctoral research fellow at the Unit of Applied Pharmacology, National Heart and Lung Institute, London, UK, and the recipient of a scholarship from Sandoz,

Switzerland.

Received September 4, 1997 Accepted October 13, 1997
Departamento de Farmacologia, Instituto de Ciências Biológicas,

Universidade Federal de Minas Gerais, Belo Horizonte, MG, Brasil

Abstract

The selective recruitment of eosinophils in tissue is a striking feature of allergic diseases. Recently, a family of chemoattractant molecules, namely chemokines, has been described which potently activates eosinophil function in vitro. We have developed a murine model of eosinophil recruitment to compare the relative potency and efficacy of chemokines in vivo. Of the chemokines tested, only eotaxin and MIP$1 \alpha$ induced significant accumulation of eosinophils in vivo, but eotaxin was more effective than MIP- $1 \alpha$. Chemokines, especially eotaxin acting via the CCR-3 receptor, may have a fundamental role in determining selective eosinophil recruitment in vivo.

Key words

- Eosinophils

- Chemokines

- Eotaxin

- MIP-1 $\alpha$

- Chemokine receptors

\section{Eosinophils as target for the} treatment of allergic diseases

There is much evidence to suggest an important role for eosinophils in the pathophysiology of parasitic and allergic diseases $(1,2)$. In the former diseases, eosinophil accumulation and activation at sites of migrating larvae may kill the parasites or render them immobile (3). In addition, epidemiological studies suggest a relationship between eosinophil levels in blood and protection against parasitic diseases (2). However, in allergic diseases, such as atopic dermatitis and asthma, uncontrolled eosinophil activation may lead to the release of lipid mediators, basic proteins, reactive oxygen species and cytokines (4). For example, in asthma these eosinophil products may cause bronchoconstriction, damage the respiratory epithelium and contribute to airway hyperresponsiveness (5).

A striking feature of allergic diseases is the presence of a great number of eosinophils in tissue in the absence of a significant number of neutrophils (5). This preferential accumulation of eosinophils suggests the existence of specific pathways used by eosinophils, but not by neutrophils, for their specific accumulation in vivo. An understanding of the particular mechanisms modulating eosinophil recruitment in vivo would aid in the development of pharmacological therapies which would specifically block the recruitment of eosinophils, but not of other leukocytes (6). Such therapies may be of benefit in allergic diseases where inhibition of eosinophil recruitment is desirable, but without the side effects of current therapies (e.g., steroids) which inhibit leukocyte recruitment indiscriminately.

\section{Mechanisms of eosinophil recruitment}

In response to extravascular injurious 
stimuli, circulating leukocytes have to interact with endothelial cells prior to leaving blood vessels and entering the interstitium. The current paradigm for the accumulation of leukocytes into tissues of the systemic circulation predicts the presence of at least three stages of leukocyte/endothelial cell interaction $(7,8)$ (see Figure 1). Although this paradigm has been demonstrated more extensively for neutrophil and lymphocyte recruitment in vivo, similar mechanisms are thought to be important for eosinophils (6). Initially, the circulating leukocytes are captured and roll on the endothelial cells of post-capillary venules, a process mediated by selectins present on the leukocytes (Lselectin) and endothelial cells ( $\mathrm{P}-$ and $\mathrm{E}-$ selectin) and their carbohydrate ligands (e.g., PSGL-1, ESL-1 and CD34) (8,9). The integrin VLA-4 may also play a role in mediating the rolling of VLA-4-positive cells (such as eosinophils) in vivo (10). The rolling leukocytes may then be activated by chemoattractants (e.g., eotaxin, interleukin-8, PAF) which leads to upregulation and increased avidity of integrins present on the leukocyte surface (e.g., CD11/CD18 and VLA-4) (7). These molecules mediate the firm adhesion of activated leukocytes to endothelial cells by binding to ligands including ICAM-1 and VCAM-

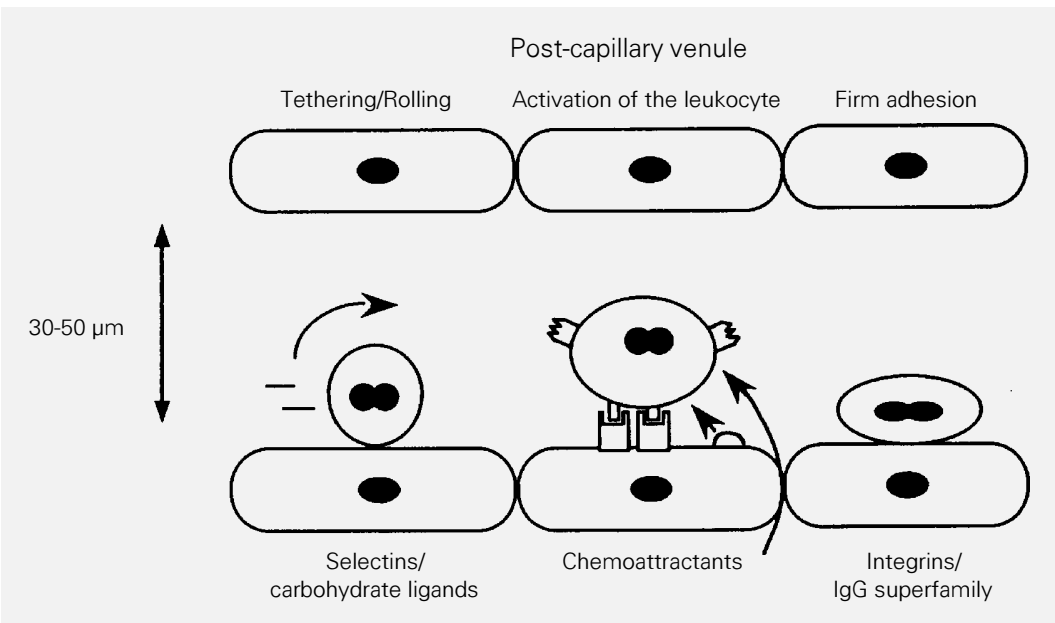

Figure 1 - The three-step model for the migration of blood leukocytes into tissue of the systemic circulation.
$1(8)$. The leukocytes are then able to migrate to the interstitium, a process that also involves PECAM-1 (CD31) (8).

\section{Eosinophil-active chemokines}

Of special interest to this review is the recent discovery of a family of chemoattractants, namely chemokines (chemoattractant cytokines), a few of which are potent activators of eosinophils (Table 1). Chemokines are proteins of molecular mass usually ranging from 8 to $10 \mathrm{kDa}$ and amino acid sequence identity of 20 to $90 \%$ (11). These proteins have four conserved cysteine residues and, depending on the presence of one amino acid between the first two cysteines, are classified into $\mathrm{C}-\mathrm{C}$ (no amino acid) and $\mathrm{C}-\mathrm{X}-\mathrm{C}$ (one intervening amino acid) chemokines (11). More recently, a member (lymphotactin) of a third subfamily, $\mathrm{C}$ chemokines, has been identified which possesses only two cysteine residues (11). The main function of chemokines appears to be related to the selective activation and recruitment of particular leukocyte subsets, but a number of different roles have been ascribed to these proteins $(11,12)$. Chemokines act on distinct 7-membrane spanning $G$ protein-coupled receptors on the surface of leukocytes $(13,14)$.

There are two receptors which mediate the actions of C-X-C chemokines and these receptors appear to be expressed mainly, although not exclusively, on neutrophils $(13,14)$. As such, C-X-C chemokines are potent activators of neutrophil function and recruitment and are thought to play an important role in acute inflammation (13). There are five receptors which mediate the actions of C-C chemokines and these receptors are differentially expressed on monocytes, $B$ and $\mathrm{T}$ lymphocytes, eosinophils, and basophils, amongst other cell types $(13,14)$. For example, eosinophils express high levels of the CCR-3 receptor (40,000 to 400,000 receptors per cell) and this receptor appears to mediate the action of eotaxin, RANTES and 
MCP-3 on eosinophils $(15,16)$. Interestingly, CCR-3 is the only eotaxin receptor identified to date. Eosinophils also express the CCR-1 receptor but only at $1-5 \%$ of the levels of CCR-3 (16) and, thus, it is likely that CCR-3 is largely responsible for mediating the effects of eotaxin, RANTES, MCP-3 and MCP-4 on eosinophils (17) (Table 1).

In agreement with their ability to bind to and activate the CCR-3 receptor, RANTES, MCP-3, MCP-4 and eotaxin are effective activators of eosinophils in vitro (18-21). Thus, these chemokines have been shown to elevate intracellular calcium levels in eosinophils and induce chemotaxis, mediator release and the production of oxygen radicals. In addition, it is now evident that elevated levels of these chemokines are found in tissue samples obtained from patients with allergic diseases (22,23). Both MCP-2 (24) and MIP-1 $\alpha$ (19) have also been shown to activate human eosinophils but they are considerably less effective than MCP-3, MCP-4, RANTES and eotaxin (17). MCP-2 recognizes a similar receptor to that of MCP-3 (CCR-3) but it has lower receptor affinity (24). MIP-1 $\alpha$ does not activate the CCR-3 receptor (22) and is likely to activate eosinophils via the CCR-1 receptor. Furthermore, there is evidence to suggest that both RANTES and MCP-3 may also activate the CCR-1 receptor in eosinophils inasmuch as RANTES- and MCP-3-induced intracellular calcium elevation in eosinophils is fully desensitized only after activation of these cells with MCP-2 (CCR-3) and MIP-1 $\alpha$ (CCR-1) $(19,24)$.

In vivo studies in a murine model of eosinophil recruitment

In contrast to the many studies evaluating the effect of chemokines in vitro, there have been very few investigations assessing the effects and importance of chemokines for eosinophil recruitment in vivo. Indeed, eotaxin was the only $\mathrm{C}-\mathrm{C}$ chemokine whose discovery was based on an in vivo assay (20). Moreover, there have been no studies assessing the comparative potency of eosinophil-active chemokines in vivo.

Using eosinophils purified from the blood of mice overexpressing the murine IL-5 gene (25), we have developed a murine model to compare the potency and effectiveness of eosinophil-active chemokines in vivo (26). A number of different recombinant murine C-X-C (KC, MIP-2) and C-C (mMCP$1 / \mathrm{JE}$, mMIP-1 $\alpha$, mMIP-1ß, mEotaxin, mRANTES) chemokines were tested for their ability to induce eosinophil recruitment in vivo. Only eotaxin and MIP- $1 \alpha$ induced significant eosinophil recruitment but eotaxin was more effective than MIP- $1 \alpha$ at the doses tested ( 0.3 to $30 \mathrm{pmol} / \mathrm{site})$. None of the $\mathrm{C}$ $\mathrm{X}-\mathrm{C}$ chemokines induced any significant migration of eosinophils into skin sites. In agreement with the data using [ $\left.{ }^{111} \mathrm{In}\right]$-labelled eosinophils, histological sections of skin sites injected with eotaxin and MIP- $1 \alpha$ showed significant infiltration of endogenous eosinophils. In contrast, histological sections of

Table 1 - List of members of the chemokine superfamily.

The murine homologues of human chemokines are given within parenthesis. ${ }^{\#} \mathrm{C}-\mathrm{C}$ chemokines shown to be potent activators of eosinophils mainly via the CCR-3 receptor. ${ }^{\circledR} \mathrm{C}-\mathrm{C}$ chemokines shown to activate eosinophils but less potently than \#. +IL-8 induces the chemotaxis of IL-5primed eosinophils (e.g., Ref. 34). Not shown is the $\mathrm{C}$ chemokine lymphotactin (11)

\begin{tabular}{|c|c|}
\hline C-C chemokines & C-X-C chemokines \\
\hline RANTES\# (mRANTES) & IP-10 (crg-2) \\
\hline MIP-1 $\alpha^{@}(\mathrm{mMIP}-1 \alpha)$ & Mig (mMig) \\
\hline MIP-1ß (mMIP-1ß) & NAP-4 \\
\hline MIP-1 $\gamma(\mathrm{mMRP}-2)$ & IL-8 $8^{+}$ \\
\hline MCP-1 (mMCP-1/JE) & PF-4 \\
\hline MCP-2@ & ENA-78 (LIX) \\
\hline MCP-3\# (MARC) & GCP-2 \\
\hline MCP-4\# & $\mathrm{GRO} \alpha(\mathrm{KC})$ \\
\hline Eotaxin\# (mEotaxin) & GROß/GRO $\gamma$ (MIP-2) \\
\hline I-309 (TCA-3) & SDF-1 \\
\hline HCC-1 & NAP-2 \\
\hline $\mathrm{C}-10(\mathrm{mC}-10)$ & \\
\hline
\end{tabular}


skin sites injected with $\mathrm{C}-\mathrm{X}-\mathrm{C}$ chemokines showed an intense inflammatory infiltrate consisting mainly of neutrophils but without any significant eosinophil infiltration. Similarly, the only human recombinant proteins to induce significant eosinophil recruitment into mouse skin were hEotaxin and hMIP$1 \alpha$, but not hRANTES, hMCP-1, hMCP-3 or hMCP-4.

The data demonstrating potent effects of mEotaxin in mouse skin are in good agreement with studies showing the efficacy of eotaxin in guinea pig and primate skin $(20,22,27)$. More recently, the human homologue of guinea pig eotaxin has been cloned $(20,23)$ and shown to be upregulated at sites where eosinophil infiltration occurred (e.g., nasal polyps) and after cytokine-induced stimulation of various cell lines. Similarly, in guinea pigs and mice eotaxin is expressed in the lungs after antigen challenge of sensitized animals and its expression parallels eosinophil infiltration (28-30). As on human eosinophils, it is also likely that mEotaxin activates the murine homologue of CCR-3 on eosinophils (31). Although eotaxin provides an exciting new mechanism to explain tissue eosinophilia, studies using eotaxin knock-out technology, anti-eotaxin antibodies or CCR-3 receptor blockers are needed to prove this concept.

Interestingly and in contrast to its relative low effectiveness at activating human eosinophils, MIP-1 $\alpha$ was effective at inducing eosinophil recruitment in mouse skin. This is consistent with the ability of MIP- $1 \alpha$ to bind to murine eosinophils and induce their chemotaxis in vitro (31). In addition, blocking studies have shown an important role for MIP- $1 \alpha$ in mediating eosinophil migration to the lungs of antigen-challenged mice (32). It is unclear whether MIP- $1 \alpha$ activates murine eosinophils via the CCR-1 or the CCR3 receptors. However, it has been suggested that mCCR-3 may play a more important role in the effects of MIP- $1 \alpha$ on eosinophils, inasmuch as MIP-1ß, which also binds to mCCR-1, fails to activate murine eosinophils (31). Another interesting finding was the inability of RANTES to induce significant recruitment of eosinophils in mouse skin. This is in contrast to data which have shown RANTES to activate human eosinophils and to induce eosinophil recruitment in primate and dog skin, albeit with high doses of this chemokine $(22,33)$. RANTES also failed to activate guinea pig eosinophils, even though it bound to eotaxin receptors on the surface of these cells (20).

\section{Conclusion}

We have described a new model for the study of eosinophil recruitment in vivo. In this model, eotaxin and MIP- $1 \alpha$ are effective inducers of eosinophil migration, but eotaxin was significantly more effective than MIP$1 \alpha$. None of the other C-C and C-X-C chemokines tested induced any significant eosinophil recruitment. It is our working hypothesis that chemokines (e.g., eotaxin) that activate the CCR-3 receptor are fundamental to the process of selective recruitment of eosinophils to tissues in vivo. If this is true, drugs which block the CCR-3 receptor will provide a useful and selective treatment for allergic diseases. Studies using monoclonal antibodies are under way to evaluate this hypothesis in our murine model. 


\section{References}

1. Butterworth AE \& Thorne KJI (1993). Eosinophils and parasitic diseases. In: Smith $R$ \& Cook RM (Editors), Immunopharmacology of Eosinophils. Academic Press, London, 119-150.

2. Butterfield JH \& Leiferman KM (1993). Eosinophil-associated diseases. In: Smith R \& Cook RM (Editors), Immunopharmacology of Eosinophils. Academic Press, London, 152-192.

3. McLaren DJ (1980). Schistosoma mansoni: the Parasite Surface in Relation to Host Immunity. Research Studies Press, Chichester, UK.

4. Weller PF (1991). The immunobiology of eosinophils. New England Journal of Medicine, 324: 1110-1118.

5. Djukanovic R, Roche WR, Wilson JW, Beasley CRW, Twentyman OP, Howarth PH \& Holgate ST (1990). Mucosal inflammation in asthma. American Review of Respiratory Disease, 142: 434-457.

6. Teixeira MM, Williams TJ \& Hellewell PG (1995). Mechanisms and pharmacological manipulation of eosinophil accumulation in vivo. Trends in Pharmacological Sciences, 16: 418-423.

7. Springer TA (1994). Traffic signals for lymphocyte recirculation and leukocyte emigration: the multistep paradigm. Cell, 76 : 301-314.

8. Carlos TM \& Harlan JM (1994). Leukocyte-endothelial adhesion molecules. Blood, 84: 2068-2101.

9. Varki A (1994). Selectin ligands. Proceedings of the National Academy of Sciences, USA, 91: 7390-7397.

10. Sriramarao $P$, von Andrian $U H$, Butcher EC, Bourdon MA \& Broide DH (1994). Lselectin and very late antigen-4 integrin promote eosinophil rolling at physiological shear rates in vivo. Journal of Immunology, 153: 4238-4246.

11. Schall TJ \& Bacon KB (1994). Chemokines, leukocyte trafficking and inflammation. Current Opinion in Immunology, 6: 865-873.

12. Choe $H$, Farzan $M$, Sun $Y$, Sullivan $N$, Rollins B, Ponath PD, Wu L, Mackay CR, LaRosa G, Newman W, Gerard N, Gerard C \& Sodroski J (1996). The ß-chemokine receptors CCR 3 and CCR5 facilitate infection by primary HIV-1 isolates. Cell, 85: 1135-1148.

13. Power CA \& Wells TNC (1996). Cloning and characterization of human chemokine receptors. Trends in Pharmacological Sciences, 17: 209-213.
14. Murphy PM (1996). Chemokine receptors: structure, function and role in microbial pathogenesis. Cytokine and Growth Factor Reviews, 7: 47-64.

15. Ponath PD, Qin S, Post TW, Wang J, Wu L, Gerard NP, Newman W, Gerard C \& Mackay CR (1996). Molecular cloning and characterization of a human eotaxin receptor expressed selectively on eosinophils. Journal of Experimental Medicine, 183: 1-12.

16. Daugherty BL, Siciliano SJ, DeMartino J, Malkowitz L, Sirontino A \& Springer MS (1996). Cloning, expression and characterization of the human eosinophil eotaxin receptor. Journal of Experimental Medicine, 183: 2349-2354.

17. Kita H \& Gleich GJ (1996). Chemokines active on eosinophils: Potential roles in allergic inflammation. Journal of Experimental Medicine, 183: 2421-2426.

18. Kameyoshi Y, Dorschner A, Mallet Al, Christophers E \& Schröder J-M (1992). Cytokine RANTES released by thrombinstimulated platelets is a potent attractant for human eosinophils. Journal of Experimental Medicine, 176: 587-592.

19. Rot A, Krieger M, Brunner T, Bischoff SC, Schall TJ \& Dahinden CA (1992). RANTES and macrophage inflammatory protein $1-\alpha$ induce the migration and activation of normal human eosinophil granulocytes. Journal of Experimental Medicine, 176: 14891495.

20. Jose PJ, Griffiths-Johnson DA, Collins PD, Walsh DT, Mogbel R, Totty NF, Truong O, Hsuan JJ \& Williams TJ (1994). Eotaxin: A potent eosinophil chemoattractant cytokine detected in a guinea-pig model of allergic airways inflammation. Journal of Experimental Medicine, 179: 881-887.

21. Uguccioni $M$, Loetscher $P$, Forssmann $U$, Dewald B, Li H, Lima SH, Li Y, Kreider B, Garotta G, Thelen M \& Baggiolini M (1996). Monocyte chemotactic protein 4 (MCP-4), a novel structural and functional analogue of MCP-3 and eotaxin. Journal of Experimental Medicine, 183: 23792384.

22. Ponath PD, Qin S, Ringler DJ, Clark-Lewis I, Wang J, Kassam N, Smith H, Shi X, Gonzalo J-A, Newman W, GutierrezRamos J-C \& Mackay CR (1996). Cloning of the human eosinophil chemoattractant, eotaxin. Expression, receptor binding and functional properties provide a mechanism for the selective recruitment of eosinophils. Journal of Clinical Investigation, 97: 604-612.
23. Garcia-Zepeda EA, Rothenberg ME, Ownbey RT, Celestin J, Leder P \& Luster AD (1996). Human eotaxin is a specific chemoattractant for eosinophil cells and provides a new mechanism to explain tissue eosinophilia. Nature Medicine, 2: 449456.

24. Weber $\mathrm{M}$, Uguccioni $\mathrm{M}$, Ochensberger $\mathrm{B}$, Baggiolini M, Clark-Lewis I \& Dahinden CA (1995). Monocyte chemotactic protein MCP-2 activates human basophil and eosinophil leukocytes similar to MCP-3. Journal of Immunology, 154: 4166-4172.

25. Dent LA, Strath M, Mellor AL \& Sanderson CJ (1990). Eosinophilia in transgenic mice expressing interleukin 5 . Journal of Experimental Medicine, 172: 1425-1431.

26. Teixeira MM, Williams TJ \& Hellewell PG (1996). Recruitment of eosinophils by chemokines and other chemoattractants in an in vivo mouse model. British Journal of Pharmacology, 119: 52P (Abstract).

27. Griffiths-Johnson DA, Collins PD, Rossi AG, Jose PJ \& Williams TJ (1993). The chemokine, eotaxin, activates guinea-pig eosinophils in vitro, and causes their accumulation into the lung in vivo. Biochemical and Biophysical Research Communications, 197: 1167-1172.

28. Gonzalo J-A, Jia G-Q, Aguirre V, Friend D, Coyle AJ, Jenkins NA, Lin G-S, Katz H, Lichtman A, Copeland N, Kopf M \& Gutierrez-Ramos J-C (1996). Mouse eotaxin expression parallels eosinophil accumulation during lung allergic inflammation but it is not restricted to a Th2-type response. Immunity, 4: 1-14.

29. Jose PJ, Adcock IM, Griffiths-Johnson DA, Berkman N, Wells TNC, Williams TJ \& Power CA (1994). Eotaxin: Cloning of an eosinophil chemoattractant cytokine and increased mRNA expression in allergen-challenged guinea-pig lungs. Biochemical and Biophysical Research Communications, 205: 788-794.

30. Rothenberg ME, Luster AD, Lilly CM, Drazen JM \& Leder P (1995). Constitutive and allergen-induced expression of eotaxin mRNA in the guinea pig lung. Journal of Experimental Medicine, 181: 1211-1216.

31. Post TW, Bozic CR, Rothenberg ME, Luster AD, Gerard N \& Gerard C (1995). Molecular characterization of two murine eosinophil $\beta$ chemokine receptors. Journal of Immunology, 155: 5299-5306. 
32. Lukacs NW, Strieter RM, Shaklee CL, Chensue SW \& Kunkel SL (1995). Macrophage inflammatory protein- $1 \alpha$ influences eosinophil recruitment in antigen-specific airway inflammation. European Journal of Immunology, 25: 245-251.
33. Meurer R, van Riper G, Feeney W, Cunningham $P$, Hora $D$, Springer MS, Maclntyre DE \& Rosen H (1993). Formation of eosinophilic and monocytic intradermal inflammatory sites in the dog by injection of human RANTES but not human monocyte chemoattractant protein 1 , human macrophage inflammatory protein $1 \alpha$ or human interleukin 8 . Journal of Experimental Medicine, 178: 1913-1921.
34. Sehmi R, Cromwell O, Wardlaw AJ, Moqbel R \& Kay AB (1993). Interleukin-8 is a chemoattractant for eosinophils purified from subjects with a blood eosinophilia but not from normal healthy subjects. Clinical and Experimental Allergy, 23: 1027-1036. 